\title{
Analytical Study of the Multiplicity of Regulatory Mechanisms in the Tryptophan Operon*
}

\author{
Moisés Santillán ${ }^{\mathrm{a}}$, Eduardo S. Zeron ${ }^{\mathrm{b}}$ \\ ${ }^{a}$ Depto. de Física, Esc. Sup. de Física y Matemáticas, Instituto Politécnico Nacional, Edif. 9, \\ U.P. Zacatenco, 07738 México D.F., México \\ ${ }^{b}$ Departamento de Matemáticas, CINVESTAV-IPN, Apartado Postal 14-740, 07000 \\ México D.F., México \\ Published online: 18 March 2008 \\ (C) Society for Mathematical Biology 2007
}

In the html abstract portion of the online publication of "Analytical Study of the Multiplicity of Regulatory Mechanisms in the Tryptophan Operon" (Volume 68, Number 2, February 2006, pp. 343-359, DOI: 10.1007/s11538-005-9025-0) the last name of the second author was erroneously misspelled. The authors' names should have appeared as above. And please note that the DOI in the print version should have read DOI: $10.1007 / \mathrm{s} 11538-005-9025-0$. Springer regrets the errors.

\footnotetext{
* The online version of the original article can be found at http://dx.doi.org/10.1007/s11538-005-9025-0.
} 